\title{
Reversible left ventricular dysfunction "takotsubo" cardiomyopathy associated with pneumothorax
}

\author{
Y J Akashi, M Sakakibara, F Miyake
}

Heart 2002;87:el (http://www.heartjnl.com/cgi/content/full/87/2/el)

An 83 year old woman presented to the emergency department with chest pain and dyspnoea. Chest radiography showed pneumothorax of the left lung. Arteries were normal on coronary angiography. Left ventriculography showed asynergy of apical akinesis and basal hyperkinesis. Within 18 days, the asynergy improved without any specific treatment. In the present case the left ventricular dysfunction may have been induced by altered catecholamine dynamics as a result of pneumothorax.

R eversible left ventricular asynergy, known as "takotsubo" cardiomyopathy, has been reported relatively often. However, a thorough survey of the literature found only one report of concomitant ventricular asynergy and pneumothorax. ${ }^{1}$

\section{CASE PRESENTATION}

An 83 year old woman presented to the emergency department with chest pain and dyspnoea on exertion. She had experienced spontaneous pneumothorax of the right lung 50 years earlier. One day before presentation, she had a refractory cough and developed progressive dyspnoea. On admission physical examination revealed a blood pressure of $148 / 103 \mathrm{~mm} \mathrm{Hg}$, a temperature of $36.5^{\circ} \mathrm{C}$, and tachypnoea. Laboratory tests found the following values: leucocyte count $17.7 \times 10^{9} / \mathrm{l}$, haemoglobin $1.31 \mathrm{~g} / \mathrm{l}$, platelet count $157 \times 10^{9} / \mathrm{l}$, creatine kinase $377 \mathrm{U} / \mathrm{l}$, creatine kinase MB $34 \mathrm{U} / \mathrm{l}$, and C reactive protein $0.06 \mathrm{mg} / \mathrm{l}$. Electrocardiography showed sinus tachycardia at 134 beats/min and ST segment elevation in leads V2 through V5 (fig lA). Chest radiography showed pneumothorax of the left lung (fig 1B). Echocardiography showed akinesis of the left ventricle except the basal area. After insertion of a chest drain to the left thoracic cavity, cardiac catheterisation was performed. Coronary angiography showed no significant stenosis, while left ventriculography showed asynergy of apical akinesis and basal hyperkinesis (fig 2). The dyspnoea and chest pain improved very rapidly with the water sealed drainage system. No treatment was given to maintain haemodynamics from the acute phase. The initial change in ECGs was noted 12 hours after admission. ST segment elevation in leads II, III, and aVF continued for two weeks followed by deep inverted T waves in all leads (fig 3). On hospital day 18, the left ventricular asynergy improved without any specific treatment, such as catecholamines or angiotensin converting enzyme inhibitors.

The plasma brain natriuretic peptide concentration was measured throughout the clinical period. Brain natriuretic peptide concentration was $1330 \mathrm{pg} / \mathrm{ml}$ on the first hospital day, increased to $1630 \mathrm{pg} / \mathrm{ml}$ a week later, and then began to decrease rapidly. However, the plasma noradrenaline (norepinephrine) concentration was constantly high throughout the clinical period. Concentrations of creatine kinase and creatine kinase $\mathrm{MB}$ were not increased after the initial measurement on admission.

${ }^{123}$ I-metaiodobenzyl guanidine (MIBG) scintigraphy was performed on hospital day 10. MIBG uptake, which was calculated as the ratio of heart to mediastinum, was notably low (1.50) and MIBG washout rate was notably high $(52.4 \pm 9.5 \%)$. Follow up scintigraphy performed three months later showed normal heart to mediastinum ratio and MIBG washout rate (2.27 and $28.2 \pm 8.3 \%$, respectively).

\section{DISCUSSION}

In Japan, there have been a number of reports of reversible left ventricular dysfunction with symptoms similar to those of acute myocardial infarction but without coronary artery lesions even during the acute phase with ST segment elevation. This type of ventricular dysfunction manifests left ventricular wall motion abnormalities with apical akinesis and basal hyperkinesis, which generally return to normal within a few weeks. This reversible disease is also called "takotsubo" cardiomyopathy for the characteristic shape of left ventricular asynergy; the Japanese word "takotsubo" means an octopus fishing pot with a round bottom and a narrow neck.

Left ventricular wall motion abnormalities have been observed, especially in elderly women over 60 years of age, and in most cases some physical or mental stress precedes the onset of the symptom. These cases are associated with several clinical events, such as myocardial stunning, ${ }^{2}$ subarachnoid haemorrhage, ${ }^{3} \quad$ phaeochromocytoma, ${ }^{4} \quad$ Guillain-Barré syndrome, ${ }^{5}$ and emotional stress. ${ }^{6}$ The exact mechanisms of ventricular asynergy have not been clarified; however, multivessel coronary spasm or catecholamine cardiotoxicity has been suggested as an exciting cause.

In the present patient, manifestation of coronary spasm was excluded after coronary angiography. Besides, spasm induced ventricular dysfunction is not consistent with patent coronary arteries during the acute phase with ST segment elevation. It is known that diffuse ST segment elevation can be caused by an altered immune response associated with infection. ${ }^{5}$ It is also known that catecholamine cardiomyopathy or a high concentration of plasma noradrenaline indicates ST segment deviation on an ECG. ${ }^{7}$ Furthermore, in the literature, we did find a case of left tension pneumothorax presenting elevated ST segments. ${ }^{8}$ In the present case, however, ST segment elevation persisted even after pneumothorax improved. We suggest that in the present patient left ventricular dysfunction was induced by altered catecholamine dynamics caused by the occurrence of pneumothorax, which could be an underlying stress to increase plasma noradrenaline.

\section{Authors' affiliations}

Y J Akashi, M Sakakibara, F Miyake, Division of Cardiology, Department of Internal Medicine, St Marianna University School of Medicine, Kawasaki, Japan 


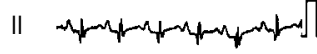
$v_{1}$ ryaryor

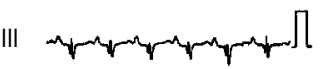

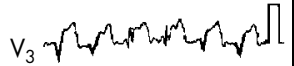

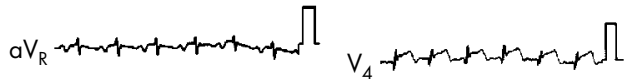

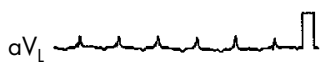

$a V_{F}$

\section{B}<smiles></smiles>

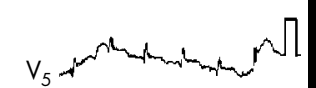
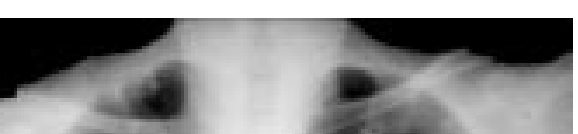

Figure 1 (A) ECG showing sinus tachycardia at 134 beats/min and ST segment elevation in leads $\mathrm{V} 2$ through V5. (B) Chest radiograph showing a pneumothorax of the left lung.
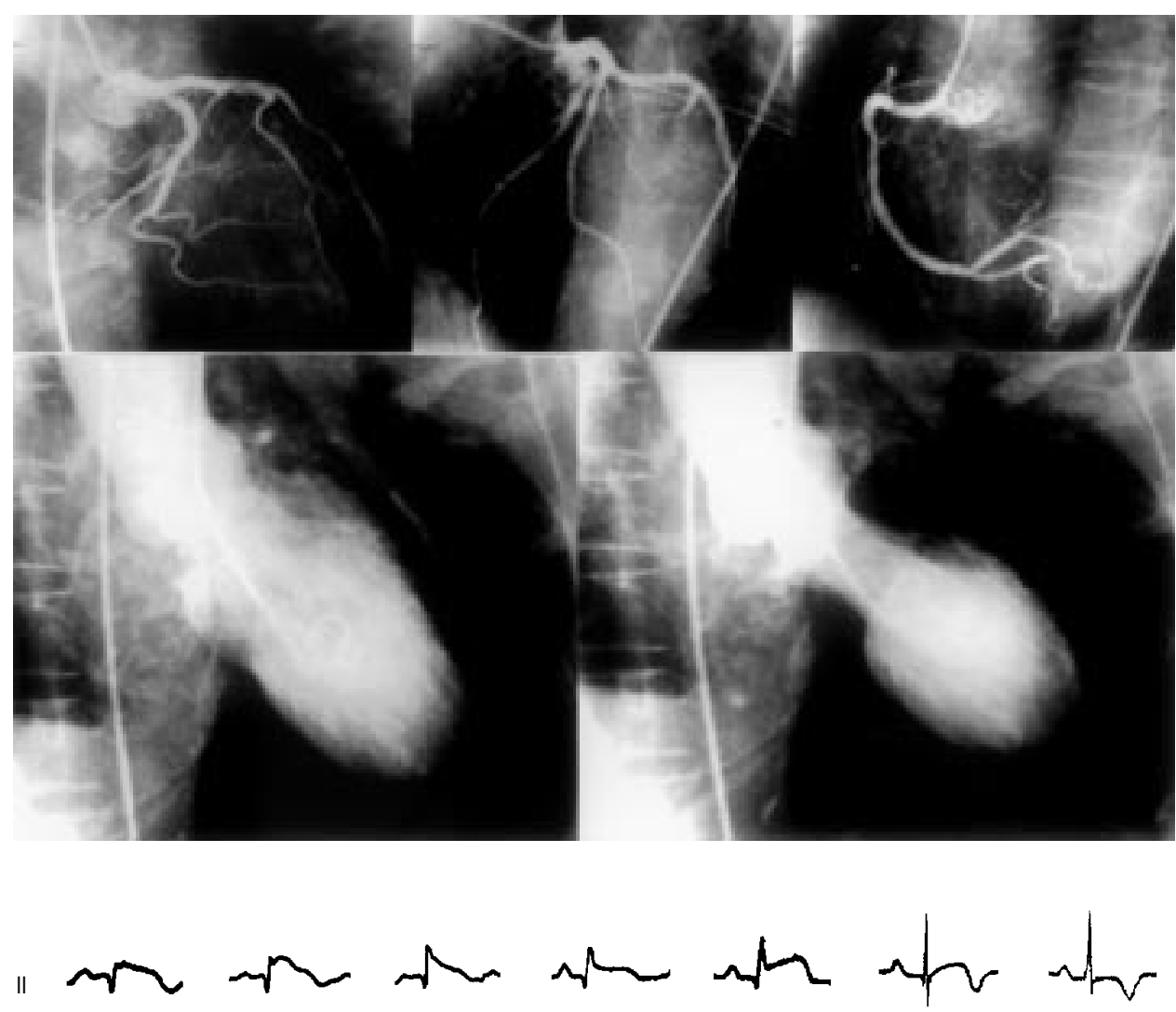

III
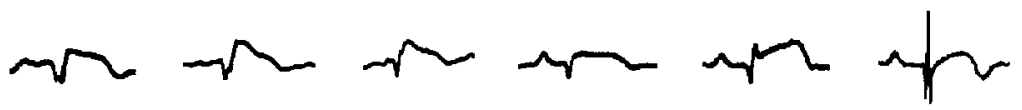

$\sim$

$\mathrm{aV}_{\mathrm{F}}$<smiles>[Y20]C[C@H](C)CCC</smiles><smiles>CCC1CCCCC1C</smiles><smiles>CCC(C)C</smiles>
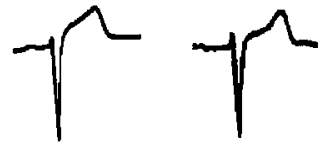

$v_{5} /$

$12 \mathrm{hr}$ sh

$48 \mathrm{hr}$

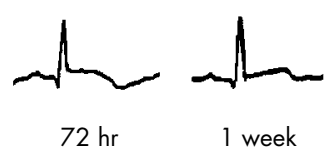

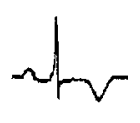
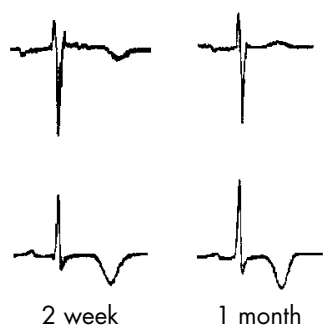

Figure 2 Coronary angiography showing no significant stenosis and left ventriculography showing asynergy of apical akinesis and basal hyperkinesis.
Figure 3 The initial change in ECG was noted 12 hours after admission.

ST segment elevation in leads II, III, and aVF continued for two weeks followed by deep inverted $T$ waves in all leads. 
Correspondence to: Dr Y J Akashi, Division of Cardiology, Department of Internal Medicine, St Marianna University School of Medicine, 2-16-1 Sugao Miyamae-ku, Kawasaki-city, Kanagawa-prefecture, 216-8511, Japan; johnny@marianna-u.ac.jp

Accepted 8 October 2001

\section{REFERENCES}

1 Yokota Y, Doi N, Sakai T, et al. Stunned myocardium induced by coronary vasospasm associated with spontaneous pneumothorax [in Japanese]. Journal of Japanese Association for Acute Medicine 2000;11:16-21

2 Braunwald E, Kloner RA. The stunned myocardium: prolonged postischemic ventricular dysfunction. Circulation 1982;66:1146-9.
3 Pollick C, Cujec B, Parker S, et al. Left ventricular wall motion abnormalities in subarachnoid hemorrhage: an echocardiographic study. J Am Coll Cardiol 1988;12:600-5.

4 Yamanaka O, Fujiwara Y, Takamura T, et al. 'Myocardial stunning'-like phenomenon during a crisis of pheochromocytoma. Jpn Circ J

$$
\text { 1994;58:737-42. }
$$

5 Iga K, Himura Y, Izumi C, et al. Reversible left ventricular dysfunction associated with Guillain-Barré syndrome: an expression of cathecolamine associated with Guillain-Barré syndrome: an

6 Case records of the Massachusetts General Hospital. Case 18-1986. N Engl J Med 1986;314:1240-7

7 Frustaci Q, Loperfido F, Gentiloni N, et al. Catecholamine-induced cardiomyopathy in multiple endocrine neoplasia: a histologic, ultrastructural, and biochemical study. Chest 1991;99:382-5.

8 Werne CS, Sands M. Left tension pneumothorax masquerading as anterior myocardial necrosis. Ann Emerg Med 1985;14:164-6. 